\title{
A hands-on microsurgery course for nurses
}

\author{
Mala Satkunanantham, Sreedharan Sechachalam \\ Department of Hand and Reconstructive Microsurgery, Tan Tock Seng Hospital, Singapore
}

\begin{abstract}
Microsurgical procedures are time-consuming and sometimes fatigue-inducing. However, a skilled assistant and scrub nurse can help surgery be performed more smoothly and rapidly. Three microsurgical simulation courses were held for perioperative nurses at our institution. Each course consisted of two lectures and two practice microsurgical sessions, and was evaluated with a post-course survey. The respondents all felt that their knowledge of microsurgical instruments, sutures, microscope set-up, and microsurgical skills had improved following the course. Many felt that their ability to predict what the surgeon would request during a microsurgical case improved, and that they were able to handle instruments and sutures better. The nurses also reported improved confidence in assisting with microsurgical procedures and tolerance of the long operative time in some microsurgical cases. Based on our experience, a basic microsurgery course for nurses can play a significant role in training effective and competent microsurgical scrub nurses.
\end{abstract}

Keywords Microsurgery / Medical education / Nurses

\author{
Correspondence: \\ Mala Satkunanantham \\ Department of Hand and \\ Reconstructive Microsurgery, Tan Tock \\ Seng Hospital, 11 Jalan Tan Tock Seng, \\ Singapore 308433 , Singapore \\ Tel: $+65-63577714$ \\ Fax: +65-63577715 \\ E-mail: malasatku@gmail.com
}

This article was presented at the European Federation of Societies for Microsurgery on April 3-5, 2014, in

Barcelona, Spain.

We would like to acknowledge our Nursing Officer for assisting with the distribution and collection of surveys.

\section{INTRODUCTION}

Microsurgical procedures are time-consuming and sometimes fatigue-inducing. Fatigue increases the risk of poorer-quality vascular anastomoses and nerve repair, and even failure of the procedure. The importance of a good assistant in microsurgery cannot be overemphasized. A good assistant can make the operation a smoother and faster process by retracting soft tissue and holding the vessels and nerves in an optimal position for placing sutures and cutting sutures under microscopic magnification.

Scrub nurses' roles have traditionally included preparation of surgical instruments, sterile supplies, and trolleys, as well as maintaining a sterile environment and facilitating surgery [1]. Over time, scrub nurses' responsibilities have evolved [2] due to personnel issues such as the lack of sufficient assistant surgeons, the increasing number of surgical procedures, and increased training and specialization for nurses.

In our unit's experience, there is often sufficient personnel in the theatre for elective microsurgical procedures such as free flap surgery. However, during emergency procedures requiring microsurgery, sometimes the only surgical assistant available is the scrub nurse. These procedures include replantation surgery, critical revascularization of the upper limb, and nerve repair. Ironically, the primary surgeons in these emergency procedures tend to be more junior and have a higher likelihood of operating late at night.

We introduced a hands-on microsurgery workshop for scrub nurses to increase their exposure and knowledge about microsurgical cases, as well as increase their confidence and understanding of assisting with microsurgical cases. 


\section{IDEA}

\section{Course}

Our course components were planned to satisfy the primary aim of training our scrub nurses to serve as microsurgical assistants. Each course was 4 hours long and consisted of two 15-minute lectures and two 1-hour practical sessions with a 20-minute break, as shown in Fig. 1. Each course was designed to accommodate up to 10 participants and had four to six instructors (Fig. 2).

\section{Course requirements}

Several requirements need to be fulfilled in order to hold the course: (1) The availability of senior microsurgeons, microsurgeons, and microsurgery technicians with sufficient experience to correct mistakes and give advice on microsurgical efficiency. We found that a ratio of one facilitator to two participants was most beneficial; (2) Participants with perioperative nursing experience, with or without specific experience in assisting or setting up for microsurgery cases; (3) Equipment: (a) microscopes with features such as adjustable eye pieces and focus were used, (b) the basic set of microsurgical instruments and sutures for each participant consisted of one jeweler's forceps, one needle holder, and one pair each of straight and curved scissors, (c) specimens for microsurgery practice. Our participants started with practice on gloves, followed by practice on non-living specimen vessels; or (4) Finally, a facility or laboratory large enough to house the participants and equipment, with certification to perform courses on wet specimens is needed to hold the course.

\section{Course schedule}

The first lecture, entitled "Introduction to the Microscope and Set-Up," described the functions of the surgical microscope used

\begin{tabular}{|c|l|}
\hline & \multicolumn{1}{|c|}{ Microsurgery workshop for nurses } \\
\hline & \multicolumn{1}{|c|}{ Topic } \\
\hline Time & \\
\hline 8:30 AM & Registration \\
\hline 8:45 AM & Lecture: Introduction to the microscope and basic set-up \\
\hline & \\
\hline 9:00 AM & Lecture: Basic handling of microsurgical instruments and sutures \\
\hline & \\
\hline 9:15 AM & Practical 1: Suturing under the microscope (glove) \\
\hline & \\
\hline 10:00 AM & \\
\hline & \\
\hline 10:20 AM & Practical 2: End to end anastomosis (chicken thigh) \\
\hline & \multicolumn{2}{c}{ Tea break } \\
\hline 12:00 Noon & Course end \\
\hline
\end{tabular}

Fig. 1. Course timetable. in the operating theatre as well as how to prepare the microscope for surgical use. The lecture also identified the parts of the microscope used for the course, as well as how to operate it. The second lecture, "Basic Handling of Microsurgical Instruments and Sutures," explained how to handle the microsurgical instruments and briefly explained the basic principles of microsurgery. This was followed by a live demonstration of microsurgical suturing on a glove, then on the femoral artery of a chicken thigh under a microscope with an attached video camera. The video camera feed was displayed in real time via a projector screen.

The first practical session, "Suturing under the Microscope on a Glove," allowed participants to get used to the microscope, handling microsurgical instruments and 9-0 microsurgical sutures. Participants were given 1 hour to suture the glove along transverse, longitudinal, oblique, and curved incisions. There was a 20-minute break prior to the second practical session, "End-to-End Anastomosis on the Femoral Artery of a Chicken." The femoral artery from a fresh chicken thigh specimen was exposed (Fig. 3). Participants divided and prepared the vessel ends, then performed an end-to-end anastomosis.

\section{The survey}

Immediately after each course, each participant was given a

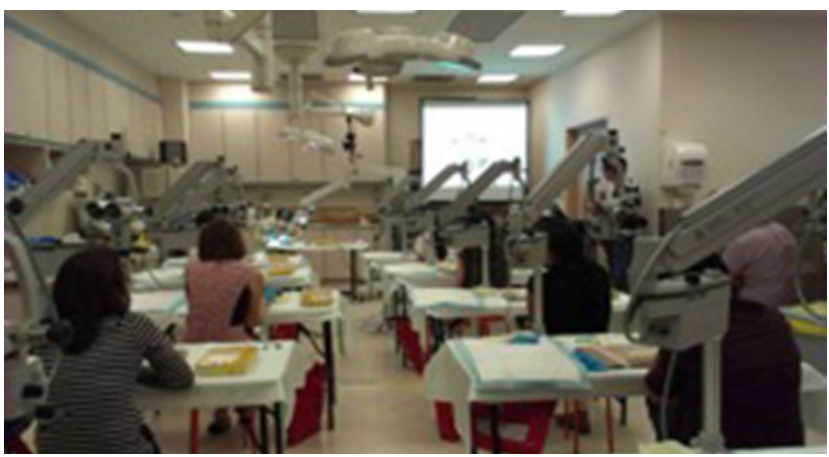

Fig. 2. The course set-up. An image of the arrangement of the tables and microscopes in the course.

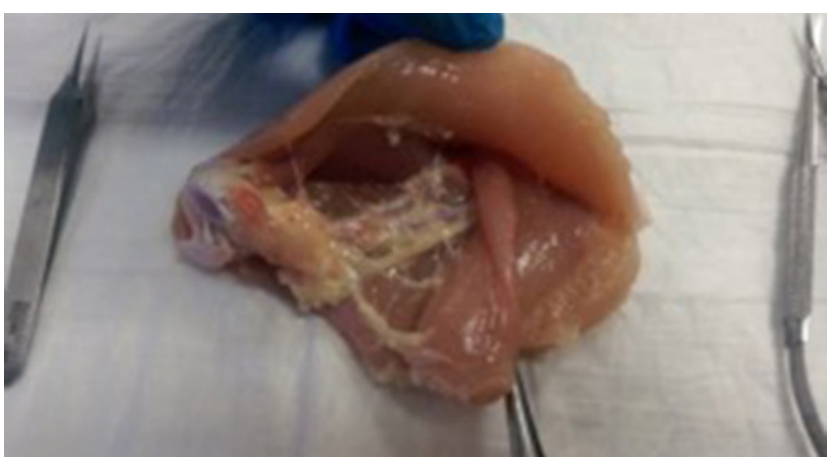

Fig. 3. Prepared chicken thigh with exposed femoral artery. Chickens used in the experiment were purchased at a mart. 


\begin{tabular}{|c|c|c|c|c|c|c|}
\hline & Questions & $\begin{array}{l}\text { Strongly } \\
\text { disagree }\end{array}$ & Disagree & Neutral & Agree & $\begin{array}{c}\text { Strongly } \\
\text { agree }\end{array}$ \\
\hline 1 & $\begin{array}{l}\text { My knowledge of the microsurgical instruments and sutures has } \\
\text { improved. }\end{array}$ & & & & & \\
\hline 2 & $\begin{array}{l}\text { My knowledge on how to use and set up the microscope has } \\
\text { improved. }\end{array}$ & & & & & \\
\hline 3 & My knowledge on microsurgery skills has improved. & & & & & \\
\hline 4 & I am more tolerant of long microsurgical cases. & & & & & \\
\hline 5 & I can better predict what the surgeon will ask for during the case. & & & & & \\
\hline 6 & I can handle the instruments and sutures better. & & & & & \\
\hline 7 & It is easier for me to use and set up the microscope. & & & & & \\
\hline 8 & $\begin{array}{l}\text { The } 1 \text { st lecture: 'Introduction to the microscope and basic setup' } \\
\text { was useful to me as a microsurgery nurse }\end{array}$ & & & & & \\
\hline 9 & $\begin{array}{l}\text { The 2nd lecture: 'Basic handling of microsurgical instruments and } \\
\text { sutures' was useful to me as a microsurgery nurse }\end{array}$ & & & & & \\
\hline 10 & $\begin{array}{l}\text { The 1st practical: 'Suturing under the microscope (glove) was } \\
\text { useful to me as a microsurgery nurse }\end{array}$ & & & & & \\
\hline 11 & $\begin{array}{l}\text { The } 2 \text { nd practical: 'End-to-end anastomosis (chicken)' was useful } \\
\text { to me as a microsurgery nurse }\end{array}$ & & & & & \\
\hline 12 & The duration of the course was adequate. & & & & & \\
\hline 13 & My interest was maintained throughout the course. & & & & & \\
\hline 14 & $\begin{array}{l}\text { The course has made it easier for me to assist microsurgical } \\
\text { cases. }\end{array}$ & & & & & \\
\hline 15 & I would attend a more advanced course on microsurgery. & & & & & \\
\hline 16 & $\begin{array}{l}\text { My experience being the 'surgeon' helps to makes me a better } \\
\text { scrub nurse. }\end{array}$ & & & & & \\
\hline \multirow[t]{2}{*}{17} & I would advise my colleagues to attend a similar course. & & & & & \\
\hline & & Very poor & Poor & Average & Good & Very good \\
\hline 18 & $\begin{array}{l}\text { How would you rate your knowledge of the subjects before this } \\
\text { programme? }\end{array}$ & & & & & \\
\hline 19 & $\begin{array}{l}\text { How would you rate your knowledge in the subjects after this } \\
\text { programme? }\end{array}$ & & & & & \\
\hline 20 & $\begin{array}{l}\text { How applicable are the skills and knowledge learnt in this } \\
\text { programme to your work? }\end{array}$ & & & & & \\
\hline
\end{tabular}

Fig. 4. Survey questions. The list of survey questions handed to each participant after the course.

20-question survey (Fig. 4), using a 5-point Likert scale for responses. All responses were included in the study. Approval for the study was obtained from our institutional review board.

\section{Survey results}

A total of 30 operating theatre scrub nurses from the divisions of general surgery, plastic surgery, otorhinolaryngology, orthopedic surgery, hand surgery, and ophthalmology participated in the workshops.

The response rate was $96.7 \%$. Their responses are shown graphically in Figs. 5 and 6.

The respondents all felt that their knowledge of microsurgical instruments, sutures, microscope set-up, and microsurgical skills had improved after the course. They would all also recommend their colleagues to attend a similar course.

The majority of respondents ( $86.2 \%)$ felt that their ability to predict what the surgeon would request during a microsurgical
Agree, strongly agree Neutral

Disagree, strongly disagree

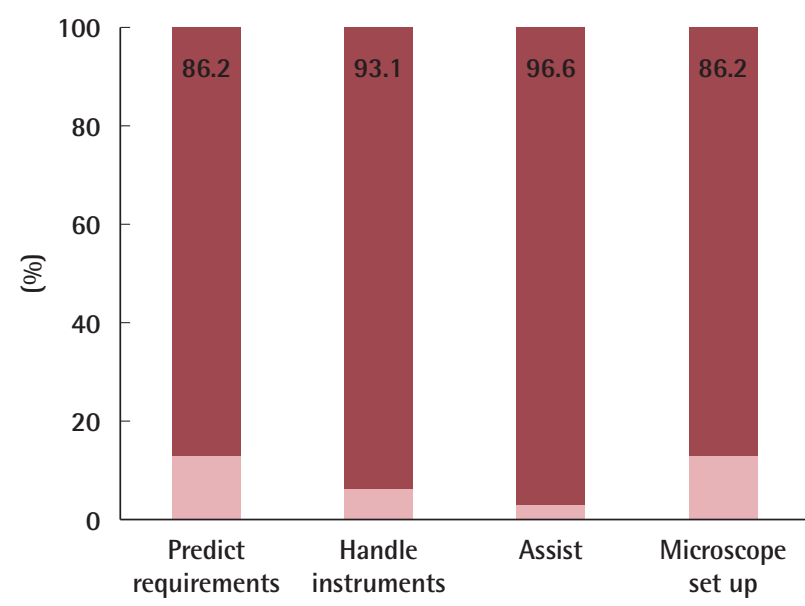

Fig. 5. Results regarding improvement. A chart of the results showing how participants felt the course helped them improve. 


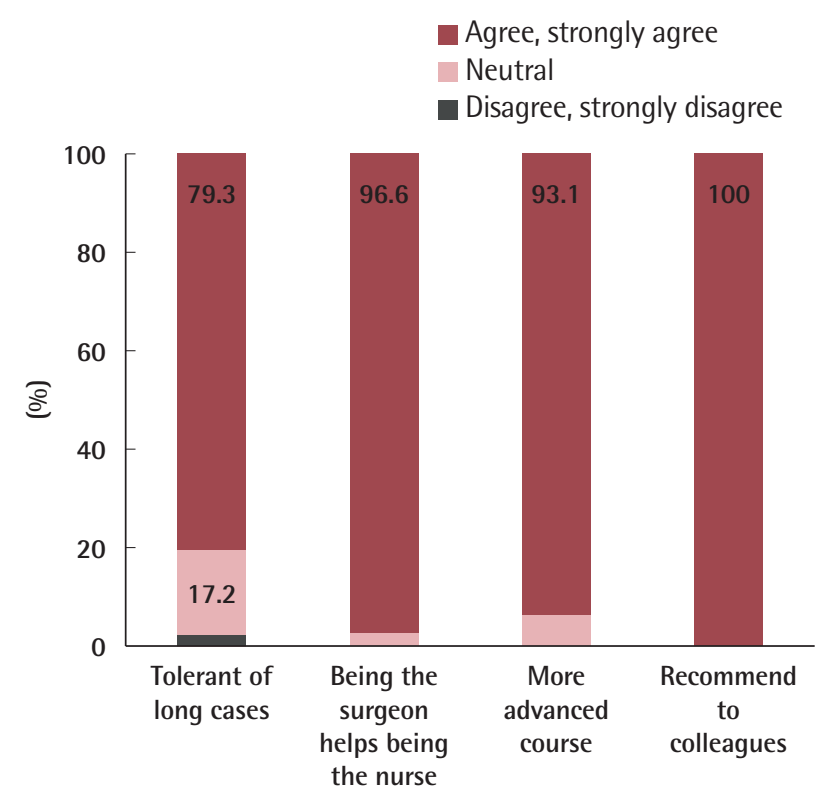

Fig. 6. Results regarding attitudes. A chart of the results showing how participants felt the course changed their attitudes towards microsurgery.

case had improved, and $93.1 \%$ felt that they were able to handle the instruments and sutures better after the course. Furthermore, $79.3 \%$ felt that they were more tolerant of long microsurgery cases.

A survey of the 30 surgeons working with these trained nurses showed that all the surgeons felt that the nurses were more careful, but also less nervous, when assisting in microsurgery. The felt that the trained nurses were also confident in handling microsurgery equipment and familiar with the steps of performing microsurgery, and were therefore able to assist better.

\section{DISCUSSION}

The principal aim of organizing a microsurgical course for our scrub nurses was to equip them with sufficient skills to assist microsurgeons. The secondary aims of organizing such a course were. First, for participants to have a formal introduction to the operating microscope and learn about its care and operation. Prior to our course, scrub nurses' knowledge of the operating microscope was based purely on observation of the surgeons and the more experienced nursing staff. We aimed to present relevant information on the microscope in a more structured manner through this course. Second, for participants to have hands-on experience with microsurgical instruments. By handling the instruments for tissue dissection, suturing, and cutting, we hoped that the importance of ensuring good care of microsurgical instruments would be reinforced to the nurses. Third, for participants to improve their non-technical skills such as empathy and situational awareness, which are pivotal in their roles in the theatre [1]. By exposing the scrub nurses to operating under the microscope, the nurses improved their ability to identify the roles of the various instruments, the steps in a particular microsurgical maneuver (e.g., suturing), and the progress towards fatigue. Fourth, for junior staff to be involved as faculty members. We included surgical trainees with microsurgical experience as part of the faculty. We believe that the observation, and hopefully, rectification, of common mistakes during microsurgery will be of value for their own microsurgical techniques.

At the end of the course, questionnaires were administered to allow us to understand whether the course had achieved some of these aims.

Our results showed that nurses' understanding of how to assist with microsurgical cases improved. The participants also reported improvements in their confidence in assisting with microsurgical cases and in their tolerance of the long operative requirements of certain microsurgical cases.

The significance of our results would be improved by using a matched pre- and post-course knowledge, attitudes, and perceptions questionnaire to demonstrate a difference. This will be incorporated in future courses. Future editions of the survey will also ascertain whether participants had prior experience in assisting microsurgical cases, as this may affect the impact of the course on the participant.

Training microsurgeons is not the aim of this course, and as such, assessment tools such as the microsurgery-specific objective global rating scales may not be relevant. Subjective feedback from microsurgeons assisted by nurses who have undergone the course has been encouraging. However, we do not currently have an objective method of measuring improvements pre- and post-course.

Hara et al. [3] described a system of rotating their nurses in various operating theatres, which trained them to be effective microsurgical assistants. While this is a better way to train nurses, we are unable to adopt a similar system. A large proportion of our microsurgical cases are emergency cases and the scrub nurse may be any one of the rostered scrub nurses; therefore, we encouraged a variety of scrub nurses in the division of surgery to attend our course. Additionally, the workload of our elective microsurgical cases is not high enough to justify dedicated microsurgery-trained scrub nurses to be rostered to our theatres for training purposes.

Flurry et al. [4] described a course for nurses involved in microsurgical management, where microsurgical training was just one component of the course. Other components of their course included postoperative management, including flap monitoring. We fully support the holistic nature of this course; 
however, we conduct a separate course on postoperative management targeting nurses who are involved in that aspect of care. In line with personnel requirements and the desire for nurses to be more actively involved in patient care, a greater degree of involvement of well-trained scrub nurses during microsurgery can potentially lead to better surgical outcomes. In our experience, a basic microsurgery course for nurses can play a significant role in that training process.

\section{NOTES}

\section{Conflict of interest}

No potential conflict of interest relevant to this article was reported.

\section{Ethical approval}

The study was approved by National Healthcare Group DomainSpecific Review Board in Singapore (IRB No. 2017/00704) and performed in accordance with the principles of the Declaration of Helsinki. This survey was anonymous. Individuals' sensitive information was not included, so the requirement to obtain written informed consent was waived.

\section{Author contribution}

Conceptualization: M Satkunanantham, S Sechachalam. Data curation, formal analysis: M Satkunanantham. Methodology: M Satkunanantham, S Sechachalam. Writing - original draft: $M$ Satkunanantham, S Sechachalam. Writing - review \& editing: $M$ Satkunanantham, S Sechachalam.

\section{ORCID}

Mala Satkunanantham https://orcid.org/0000-0002-1092-5635

Sreedharan Sechachalam https://orcid.org/0000-0002-3753-6349

\section{REFERENCES}

1. Mitchell L, Flin R. Non-technical skills of the operating theatre scrub nurse: literature review. J Adv Nurs 2008;63:1524.

2. McGarvey HE, Chambers MG, Boore JR. Development and definition of the role of the operating department nurse: a review. J Adv Nurs 2000;32:1092-100.

3. Hara T, Hara T, Takayama T, et al. A training system for first and solo assistants in microsurgery. Todays OR Nurse 1989; 11:24-9.

4. Flurry M, Brooke S, Micholetti B, et al. Nurse training with simulation: an innovative approach to teach complex microsurgery patient care. Ann Plast Surg 2012;69:459-61. 